\title{
Kajian Indeks Pembangunan Manusia (IPM); Analisa Pengaruh Rendahnya Indeks Pendidikan di Kabupaten Tangerang
}

\author{
Endang Iryani, Akhmad Subkhi Ramdani \\ Universitas Mohammad Husni Thamrin \\ (Endang.umht@gmail.com)
}

\begin{abstract}
ABSTRAK
Pendidikan merupakan faktor utama dalam membangun daerah bahkan bangsa, sehingga tinggi rendahnya indeks pendidikan memberikan salah satu indikator dalam kemajuan suatu daerah. Kabupaten Tangerang merupakan salah satu wilayah di Provinsi Banten yang memiliki pertumbuhan indeks pendidikan yang relatif rendah. Oleh karena itu penting adanya analisa untuk mengetahui faktor penyebab dari masalah rendahnya indeks pendidikan. Tujuan dari penelitian ini adalah mengetahui dampak rendahnya indeks pendidikan dan merumuskan upaya peningkatan indeks pendidikan. Metode yang digunakan pada penelitian ini adalah kualitatif dengan pendekatan Phenomology. Hasil dari penelitian menunjukan bahwa ada tiga permasalahan yang menjadikan rendahnya pendidikan di kabupaten Tangerang. Pertama, permasalahan internal orang tua dan anak sekolah. Dalam hal ini terdapat masalah: Terdapatnya anak yang putus sekolah dan sebagian besar anak hanya mengikuti pendidikan sampai SMP/MTS ataupun SMA/Madarasan Aliyah. Kedua, permasalahan pemerataan pendidikan bagi semua masyarakat. Terkait dengan pemerataan pendidikan: Kurangnya kuantitas dan kualitas guru di pedesaan, Kurangnya sarana fasilitas sekolah di pelosok desa, kurangnya mutu pendidikan di ekolah swasta, serta jurangnya manajemen sekolah swasta. Ketiga permasalahan yang terkait dengan efektifitas penyelenggaraan progam pemerintah di bidang pendidikan yakni Program BOS dan KIP yang belum efektif serta Program Kerjar Paket A,B,C belum efektif. Kesimpulan dan rekomendasi dari penelitian ini adalah pentingnya ada sinkronisasi program pemerintah dalam pendidikan dengan kebutuhan masyarakat dan melakukan evaluasi terhadap kebijakan pendidikan yang telah berjalan di kabupaten Tangerang.
\end{abstract}

\section{Keyword; Indeks Pembangunan Manusia, indeks pendidikan, IPM}

\section{Latar Belakang}

Sumber Daya Manusia (SDM) merupakan elemen dasar dalam membangun kemajuan suatu bangsa, yang berarti bahwa kemajuan suatu bangsa bergantung pada kualitas yang dimiliki oleh SDM bangsa tersebut. Sehingga pembangunan kualitas SDM sangat penting dalam membangun kemajuan bangsa, diatas pentingnya pembangunan ekonomi, sosial dan infrastruktur dalam membangun kesejahteraan bangsa.

Salah satu indikator dari keberhasilan pembangunan SDM adalah tingkat pendidikan yang didapat oleh SDM tersebut ( Rata-rata Lulusan Sekolah/RLS). Karena pendidikan merupakan kunci yang mampu meningkatkan kualitas SDM dalam membangun kesejahteraan masyarakat. Bangsa yang maju adalah bangsa yang mampu menjunjung pendidikan bagi warganya, sehingga tidak heran kalau pendidikan juga menjadi indikator dari keberhasilan pemerintahan.

Kabupaten Tangerang adalah salah satu kabupaten di Provinsi Banten yang wilayahnya sangat strategis, yakni dekat dengan ibu kota yang terhubung dengan jalan tol. Selain itu, Kabupaten Tangerang terkenal dengan wilayah seribu industri, dimana industri-industri besar terdapat di kabupaten Tangerang ini, seperti Perusahaan Elektronik LG, Perusahaan ban Gajah Tunggal, Perusahaan sepatu Nike dan lain sebagainya. Disamping itu juga, properti besar bermukim disini, seperti Citra Raya, Lippo dan Sumarecon hal ini menjadikan 
Pendapatan Asli Daerah (PAD) pada sektor pajak yang tinggi bagi kabupaten Tangerang. Selain itu juga, wilayah yang terkenal dengan warni ungu ini memiliki bandara Internasional yakni Bandara Soekarno Hatta. Akan tetapi kelebihan-kelebihan ini berbanding terbalik dengan Indeks Pembangunan Manusia (IPM) khususnya pada sektor pendidikan.

Pada tahun 2017 Indeks Pendidikan Manusia pada sektor pendidikan masih sangat rendah, tamatan Sekolah Dasar (SD) mencapai 24, 45\%, tamatan SLTP 22, 66\% ${ }^{1}$. Artinya bahwa bonus demografi dan investasi yang dimiliki oleh Pemerintah Kabupaten Tangerang tidak sebanding dengan pembangunan SDM pada sektor pendidikan. Seharusnya dengan banyaknya industri kecil sampai besar berdiri di Kabupaten Tangerang mampu memancing SDM kabupaten Tangerang memiliki angka tinggi pada pendidikan diatas SLTA, sedangkan ini hanya $4,99 \%$ artinya bahwa banyak pekerja yang berasal dari masyarakat kabupaten Tangerang adalah pekerja kasar pada industri-industri yang terdapat di Kabupaten Tangerang. Artinya, masyarakat kabupaten Tangerang menjadi tamu didaerahnya sendiri.

Landasan inilah yang menjadikan peneliti tertarik untuk meneliti faktor-faktor penyebab dari rendahnya pembangunan SDM pada bidang pendidikan. Sehingga faktor penyebab dapat dikenali dan dibuatkan solusi oleh peneliti dan menjadi rekomendasi bagi pemerintah dalam perencanaan pembangunan SDM pada tahun berikutnya.

\section{Kajian Literature}

Permasalahan yang sangat sulit adalah peningkatan Sumber Daya Manusia (SDM) dalam kualitas dan kapabilitas, dan ini artinya adalah pembangunan manusia. Salah satu cara dalam menyelesaikan masalah pembangunan manusia adalah dengan melakukan human capital atau investasi manusia. Ada tiga jenis cara dalam Human Capital yaitu (1) pendidikan dan latihan, (2) migrasi, dan (3) perbaikan gizi dan kesehatan ${ }^{2}$. Pendidikan merupakan modal dasar dalam pembangunan manusia, menurut United Nations Development Programme (UNDP), dalam Indeks Pembangunan Manusia (IPM) bahwa salah satu untuk mengukur pencapaian rata-rata suatu negara dalam pembangunan manusia adalah pendidikan yang diukur berdasarkan ratarata lama bersekolah dan angka melek huruf penduduk usia 15 tahun ke atas. IPM ini mulai digunakan oleh UNDP sejak tahun 1990 untuk mengukur upaya pencapaian pembangunan manusia suatu negara. Walaupun tidak dapat mengukur semua dimensi dari pembangunan, namun mampu mengukur dimensi pokok pambangunan manusia yang dinilai mencerminkan status kemampuan dasar (basic capabilities) penduduk. IPM pendidikan dihitung berdasarkan angka melek huruf dan rata-rata lamanya bersekolah sebagai ukuran capaian pembangunan di bidang pendidikan.

Berdasarkan Human Development Indeks (HDI) indicator yang digunakan untuk mengukur ukuran HDI adalah mencakup dua parameter yaitu angka melek huruf (LIT) dan rata-rata lama sekolah (MYS) ${ }^{3}$. Populasi yang digunakan adalah penduduk berusia 15 tahun ke atas yang bisa membaca dan menulis dalam huruf latin atau huruf lainnya. Perlunya batasan tersebut agar angkanya dapat mencerminkan kondisi sebenarnya mengingat penduduk yang berumur dibawah 15 tahun masih dalam proses sekolah akan sekolah sehingga belum pantas untuk rata-rata lama sekolahnya. Kedua parameter tersebut disertakan agar mampu menggambarkan tingkat pengetahuan (gambaran angka LIT), Dimana LIT merupakan rasio penduduk yang memiliki kemampuan baca tulis dalam suatu kelompok penduduk secara keseluruhan. Sedangkan gambaran angka MYS merupakan cerminan terhadap keterampilan yang dimiliki penduduk. ${ }^{4}$ beberapa penelitian pun telah banyak membahas mengenai IPM,

\footnotetext{
${ }^{1}$ Buku profile kab. Tangerang tahun 2017

2 Simanjuntak, Payaman. J. 2008. Pengantar Ekonomi Sumber Daya Manusia. Lembaga Penelitian FE UI. Jakarta. Hal.25

${ }^{3}$ Maulana dan Bowo 2013

${ }^{4}$ UNDP, Human Development Report, 2008
} 
ini menandakan bahwa permasalahan IPM sangatlah penting dan dianggap isu yang sangat mendasar. Berikut beberapa penelitian mengenai IPM:

Charisma Kuriata Ginting S, dkk (2008) melakukan penelitian yang berjudul "Pembangunan Manusia di Indonesia dan Faktor-Faktor Yang Mempengaruhinya". Dalam penelitian ini digunakan analisis regresi linier berganda dengan metode GLS (General Least Square). Dengan menggunakan beberapa variabel yaitu Indeks Pembangunan Manusia, pengeluaran konsumsi rumah tangga untuk makanan dan bukan makanan, rasio penduduk miskin, dan pengeluaran pemerintah untuk pendidikan. Dari penelitian dihasilkan bahwa pengeluaran konsumsi rumah tangga untuk makanan berpengaruh negatif, pengeluaran konsumsi rumah tangga untuk bukan makanan berpengaruh positif, rasio penduduk miskin berpengaruh negatif, dan pengeluaran pemerintah untuk pendidikan berpengaruh positif terhadap pembangunan manusia.

Astri Winarti (2014) dalam penelitiannya yang berjudul "Analisis Pengaruh Pengeluaran Pemerintah Bidang Pendidikan, Kemiskinan, dan PDB terhadap Indeks Pembangunan Manusia di Indonesia Periode 1992-2012"6 menggunakan empat variabel yaitu Indeks Pembangunan Manusia, Pengeluaran pemeribtah di bidang pendidikan, tingkat kemiskinan dan PDB. Penelitian menggunakan analisis regresi linier berganda. Dihasilkan bahwa variabel kemiskinan berpengaruh negatif siginfikan terhadap IPM, Variabel PDB berpengaruh positif dan signifikan terhadap IPM, sedangkan variabel anggaran pendidikan berpengaruh negatif dan tidak signifikan terhadap IPM di Indonesia.

Berdasarkan landasan teori dan review penelitian diatas maka tinjauan pustaka pada penelitian ini dapat di gambarkan dalam diagram sebagai berikut:

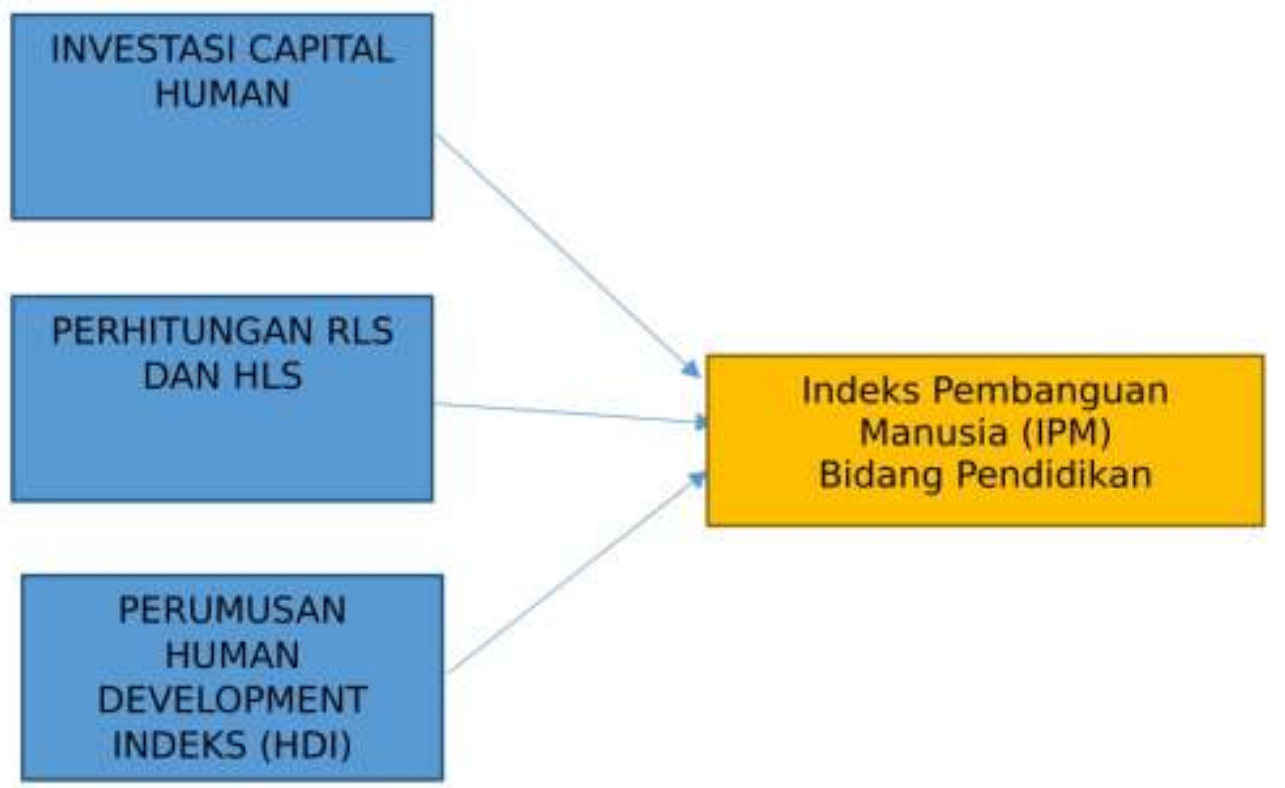

Metodologi

Penelitian ini menggunakan metode Kualitatif research dengan pendekatan Phenomologi dan Case Study. Alasan dari pemilihan metode ini adalah agar hasil penelitian mudah untuk dipahami jika penyajiannya dituangkan dalam bentuk naratif, sedangkan pendekatan

\footnotetext{
${ }^{5}$ Charisma Kuriata Ginting S, dkk (2008) melakukan penelitian yang berjudul "Pembangunan Manusia di Indonesia dan Faktor-Faktor Yang Mempengaruhinya, Economics Development Analysis Journal. Vol 1 November 2012

${ }^{6}$ Astri Winarti, Analisis Pengaruh Pengeluaran Pemerintah Bidang Pendidikan, Kemiskinan, dan PDB terhadap Indeks Pembangunan Manusia di Indonesia Periode 1992-2012. Skripsi; Repasitory Perpustakaan Universitas Diponegoro
} 
Phenomologi yakni untuk memotret kejadian yang sudah terjadi pada sektor Indeks Pembanguan Manusia (IPM) untuk sektor pendidikan di Kabupaten Tangerang, dan Case Study untuk menganalisa permasalahan yang terjadi pada IPM sektor pendidikan tersebut.

\section{Hasil Penelitian dan Pembahasan}

Berdasarkan data primer yang didapatkan melalui hasil wawancara dengan perwakilan guru, kepala sekolah, tokoh masyarakat, penyelenggara pendidikan baik di tingkat masyarakat maupun di tingkat pemerintahan sebagaimana telah dibahas di atas, maka dapat disarikan kepada hal-hal sebagai berikut:

Salah satu aspek penting dalam pelaksanaan pendidikan adalah terkait dengan pendaftaran murid baru di sekolah atau madarasah mulai dari sekolah dasar hingga sekolah menengah atas yang umumnya dilakukan dengan cara orang tua/wali murid bersama calon peserta didik mendatangi sekolah dan kemudian mengisi formulir pendaftaran ke sekolah langsung. Hal ini dipandang sudah mudah dan efektif, meskipun sering menimbulkan antrean. Untuk itu mereka mengusulkan peningkatan cara pendaftaran dengan cara sosialisasi kepada masyarakat bagaimana cara dan persyaratan pendaftaran siswa baru dan pengembangan cara pendaftaran secara online dan membuka bersite sekolah.

* Tentang pembiayaan sekolah sejalan dengan adanya program wajib belajar (wajar) 9 tahun maka pembiayaan sekolah untuk SD dan SLTP dilakukan secara gratis. Responden secara keseluruhan model pembiayaan ini meringankan orang tua siswa hingga SMP/MTS, sementara untuk tingkat SLTA dan biaya lainnya masih di tanggung oleh orang tua., untuk itu diusulkan program wajib belajar 12 tahu sehingga hingga SMA/MA.

* Tentang profesionalitas guru, responden umumnya berpendapat bahwa guru-guru yang sudah ada sudah cukup profesional, karena mereka mengajar seuai dengan keahliannya dan umumnya berpendidikan S1 Dan S2. Masalahnya adalah untuk guru-guru di pesok pedesaan yang disamping perlu oenambahan jumlahnya juga diusulkan untuk ditingkatkan profesionalismenya.

* Untuk aspek sarana dan fasilitas sekolah, para responden banyak menyoroti sarana dan fasilitas sekolah di pelosok desa yang kurang memadai dan sebagian kondisinya rusak. Untuk itu maka penambahan sekolah kshususnya sekolah tingak SLTP dan SLTA hendaknya menjadi prioritas pemerintah daerah.

* Terkait dengan program wajib belajar 9 tahun sebagai program utama pemerintah dalam meningkatkan indeks pendidikan, menurut sebagian besar responden penyelenggaraannya belum efektif. Ada bebrapa faktor penghambatnya diantaranya ; (a) masih kurangnya kesadaran sebagian masyarakat terhadap pentingnya pendidikan, (b) Kurang didukung oleh sarana, fasilitas dan guru yang memadai, khususnya di daerah terpencil. Untk itu diusulkan peningkatan kualitas dan kuantitas guru terutama di daerah terpencil, sosialisasi program wajar yang lebih intensif kepada masyarakat serta pemerataan sarana, fasilitas dan guru antara diperkotaan dan daerah pedesaan.

* Tentang pemerataan pendidikan keseluruhan responden menyatakan belum terlaksana efektif. Hal ini (a) Pendidikan (sarana, fasilitas, guru dan lainnya) di daerah terpencil minim/banyak kekurangan, (b) akses menuju dan di daerah pedesaan masih sulit dan kurang. Untuk itu diusulkan agar pemerintah derah lebih memperhatikan pendidikan di daerah terpencil baik sarana, fasilitas dan guru di daerah pelosok desa juga meingkatkan akses transportasi di wilayah pedesaan.

* Untuk pendidikan bagi kaum miskin, menurut sebagian besar responden sudah dapat dilaksanakan dengan efektif melalui program Wajib Belajar dan BOS. Menurut sebagaian besar mereka keluarga miskin sudah mendapat pendidikan dengan baik. Merek mengusulkan agar untuk meningkatkan pendidikan bagi keluarga miskin/prasejahtera diantaranya pemerataan pendidikan di kota dan pedesaan, sosialisasi wajib belajar 9 tahun, BOS dan dan lainnya agar diketahui masyarakat.

* Untuk pendidikan bagi masyarakat pedesaan menurut sebagian besar responden anak-anak dari orang tua yang tinggal di pelosok desa belum dapat menyekolahkan anaknya dengan baik, karena keterbatasan sarana dan fasilitas sekolah. Untuk itu diusulkan untuk 
meningkatkan SDM pelaku pendidikan, memperbanyak sekolah dan merenovasi sekolah di pelosok desa, serta peningkatan ekonomi masyarakat di pelosok desa.

* Menurut seluruh responden menyatakan bahwa kejadian anak putus sekolah masih terjadi di sekolah-sekolah yang terdapat di Kabupaten Tangerang. Penyebab dominan karena masalah ekonomi keluarga dan karena faktor kurangnya kesadaran orang tua dan motivasi anak. Untuk itu diusulkan adanya penyuluhan kesadaran tentang pentingnya pendidikan kepada orang tua, sosialisasi program wajar 9 tahun, peningkatan program wajar jadi 12 tahun.

* Salah satu program untuk mendukung peningkatan indeks pendidkan secara langsung adalah Program Paket A,B dan C. Menurut sebagian besar responden pelaksanaanya belaum efektif karena belum banyaknya masyarakat yang mengetahui dan masalah pembiayaan yang memberatkan dan pengurusan ijazah kesetaraan yang sering merasa kesulitan. Mereka mengusulkan adanya sosialisasi program Paket A,B, C secara merata dan memberikan kemudahan dalam pengurusan ijazah persamaan.

* Program lainnya untuk mendukung peningkatan Wajar 9 tahun dan indeks pendidikan adalah program BOS dan Kartu Pintar, yang menurut sebagian besar responden belum efektif. Alasanya belum efektif masih ada sekolah yang kurang transparan atau terbuka terhadap pengeloan dana BOS serta ada bantuan yang kurang tepat sasaran. Agar lebih efektif, maka perlu peningkatan sosialisasi program BOS dan KIP, peningkatan transparansi dalam pengelolaan dana BOS dan KIP, serta peningkatan monitoring dan pengawasan pemanfaatn dana BOS dan KIP.

* Dalam penyeleggaraan dan memajukan pendidikan di Kabupaten Tangerang terdapat beberapa kendala. Kendala itu adalah kondisi bangunan dan fasilitas pendidikan yang kurang, kuranya tenaga pendidik, sarana dan fasilitas sekolah di daerah pelosok, kesenjangan antara pendidikan di desa dan kota, pendidikan yang belum merata, tenaga pendidik yang kurang, masalah ekonomi keluarga dan tingkat kesadaran orang tua terhadap pendidikan yang kurang.

Untuk meningkatkan indeks pendidikan di Kabupaten Tangerang, maka diperlukan strategi yang disusun dengan mengacu pada pengembangan kekuatan dan potensi pendidikan yang terdapat di Kabupaten Tangerang, memanfaatkan sebesar-besar-besarnya peluang yang dimiliki serta menutupi kekurangan dan kelemahan serta menolak ancaman dari luar yang dapat menggalkan tujuan pendidikan dan upaya-upaya untuk peningkatan indeks pendidikan.

Strategi dan program peningkatan indeks pendidikan ini disusun berorientasi pada sararan sebagai berikut:

1) Meningkatnya mutu pendidikan dengan pemerataan guru dan pengembangan sarana dan fasilitas pendidikan pada jenjang pendidikan dasar, menengah dan pendidikan tinggi

2) Percepatan pencapaian pemerataan pendidikan dan pencapaian program wajar 9 tahun menuju wajar 12 tahun

3) Berkurangnya kesenjangan pendidikan antara perkotaan dan pedesaan serta antara pendidikan di sekolah swasta dan negeri baik dalam mutu pendidikan maupun sarana, fasilitas dan ketersediaan pendidik.

4) Optimalisasi program dana BOS, Program Penyetaraan Paket A,B,C dan Program Indonesia Pintar (PIP) untuk mencegah dan menanggulangi anak putus sekolah dan mendukung peningkatan indeks pendidikan

5) Berkembangnya peran serta masyarakat, organisasi masyarakat dan kelembagaan/organisasi masyarakat dalam peningkatan pelaksanaan pendidikan formal dan pelaksanaan program wajar dan penyetaraan guna peningkatan indeks pendidikan

Secara rinci, strategi yang bisa diterapkan untuk meningkatkan inedeks pendidikan, berikut ini strategi prioritas, program berikut indikasi kegiatan untuk peningkatan indeks pendidikan di Kabupaten Tangerang: 


\section{Tabel Setrategi dan Program Akselerasi Peningkatan Indeks Pendidikan di Kabupaten Tangerang}

\begin{tabular}{|c|c|c|c|}
\hline No & Program & Setrategi & Indikasi Kegiatan \\
\hline 1 & $\begin{array}{l}\text { Pencegahan dan } \\
\text { penanggulangan } \\
\text { anak putus } \\
\text { sekolah }\end{array}$ & $\begin{array}{l}\text { Pemantauan dan peningkatan } \\
\text { motivasi orang tua dan anak } \\
\text { rentan putus sekolah, serta } \\
\text { peningkatan kerjasama } \\
\text { sekolah dengan PKBM dan } \\
\text { kelembagaan masyarakat } \\
\text { untuk mengantisipasi anak } \\
\text { putus sekolah }\end{array}$ & $\begin{array}{l}\text { - Pemantauan dan deteksi dini anak rentan putus sekolah di } \\
\text { sekolah-sekolah } \\
\text { Penyuluhan pentingnya pendidikan bagi keluarga dari anak yang } \\
\text { rentan putus sekolah } \\
\text { BP sekolah rutin memberikan motivasi khusus kepada anak yang } \\
\text { rentan putus sekolah } \\
\text { Memfasilitasi anak yang terlanjur putus sekolah untuk mengikuti } \\
\text { Program Kejar Paket } \\
\text { Memberi prioritas bagi anak dari keluarga miskin rentan putus } \\
\text { sekolah untuk ditanggung seluruh biaya sekolahnya melalui PIP }\end{array}$ \\
\hline 2 & $\begin{array}{l}\text { Peningkatan } \\
\text { kelulusan } \\
\text { pendidikan Anak } \\
\text { minimal SMA/MA }\end{array}$ & $\begin{array}{l}\text { Perintisan program wajar } 12 \\
\text { tahun serta peningkatan } \\
\text { motivasi orang tua dan anak } \\
\text { untuk melanjutkan pendidikan } \\
\text { hingga perguruan tinggi }\end{array}$ & $\begin{array}{l}\text { Rintisan Program Wajar hingga } 12 \text { tahun atau pendidikan gratis } \\
\text { hingga SMA/MA } \\
\text { Pendataan kelulusan dan kelanjutan sekolah anak di sekolah } \\
\text { SD/MI dan SMP/MTS } \\
\text { Aptimalisasi peran BP Sekolah untuk memotivasi anak } \\
\text { melanjutkan pendidikan sampai Perguruan Tinggi }\end{array}$ \\
\hline 3 & $\begin{array}{l}\text { Peningkatan } \\
\text { Pemerataan } \\
\text { pendidikan antara }\end{array}$ & $\begin{array}{l}\text { Peningkatan kualitas dan } \\
\text { kuantitas guru serta sarana } \\
\text { dan fasilitas pendidikan } \\
\text { dengan prioritas di pedesaan }\end{array}$ & $\begin{array}{l}\text { Penambahan guru-guru yang bertugas di pelosok desa } \\
\text { Memberikan insentif khusus bagi guru-guru yang bertugas di } \\
\text { pelosok desa }\end{array}$ \\
\hline
\end{tabular}

6IFakultas Keguruan dan IImu Pendidikan Univ. MH Thamrin 


\begin{tabular}{|c|c|c|c|}
\hline & $\begin{array}{ll}\text { kota } & \text { dan } \\
\text { pedesaan } & \end{array}$ & & $\begin{array}{l}\text { Penambahan sekolah di pelosok desa, khususnya untuk jenjang } \\
\text { SMP/MTS dan SMA/MA/SMK } \\
\Rightarrow \text { Pemantauan kondisi sekolah dan fasilitas pendidikan serta } \\
\text { identifikasi kebutuhan perbaikan dan penambahan sarana dan } \\
\text { fasilitas pendidikan }\end{array}$ \\
\hline 4 & $\begin{array}{l}\text { Peningkatan mutu } \\
\text { pendidikan dasar } \\
\text { dan menengah }\end{array}$ & $\begin{array}{lr}\text { Peningkatan } & \text { kualitas } \\
\text { pendidikan, tenaga pengajar } \\
\text { serta sarana dan fasilitas } \\
\text { pendidikan dasar } \\
\text { menengah }\end{array}$ & $\begin{array}{l}\text { क Pengadaan sarpras pendidikan dasar dan menengah. } \\
\text { Pemerataan kuantitas dan kualitas tenaga pendidikan dasar dan } \\
\text { menengah. } \\
\Rightarrow \text { Rintisan program wajar } 12 \text { tahun } \\
\Rightarrow \text { Peningkatan kuantitas dan kompetensi peserta didik pada } \\
\text { sekolah kejuruan. } \\
\Rightarrow \text { Penambahan dan rehab ruang belajar sekolah sesuai kebutuhan } \\
\Rightarrow \text { Perbaikan fasilitas KBM, perpustakan, laboratorium dan fasilitas } \\
\text { kegiatan ekstra kurikuler }\end{array}$ \\
\hline 5 & $\begin{array}{l}\text { Penyetaraan mutu } \\
\text { pendidikan swasta } \\
\text { dengan sekolah } \\
\text { negeri }\end{array}$ & $\begin{array}{l}\text { Pendampingan dan pelatihan } \\
\text { peningkatan manajemen } \\
\text { pendidikan/sekolah } \\
\text { pengurus dan pagi } \\
\text { yayasan pengelola } \\
\text { swasta }\end{array}$ & $\begin{array}{l}\text { Pendampingan (asistensi) pengembangan mutu pendidikan dan } \\
\text { manajemen sekolah-sekolah swasta } \\
\text { Pendidikan dan pelatihan pengembangan mutu pendidikan dan } \\
\text { manajemen bagi Kepala Sekolah, Guru dan Tenaga Administrasi } \\
\text { Sekolah Swasta } \\
\text { Kerjasama sekolah swasta dengan sekolah negeri dalam } \\
\text { pengembangan mutu pendidikan }\end{array}$ \\
\hline
\end{tabular}

7|Fakultas Keguruan dan IImu Pendidikan Univ. MH Thamrin 


\begin{tabular}{|c|c|c|c|}
\hline 6 & $\begin{array}{l}\text { Peningkatan } \\
\text { efektifitas } \\
\text { pengelolaan dana } \\
\text { BOS }\end{array}$ & $\begin{array}{l}\text { Peningkatan pengelolaan dana } \\
\text { BOS yang lebih tranparan dan } \\
\text { tepat sasaran }\end{array}$ & 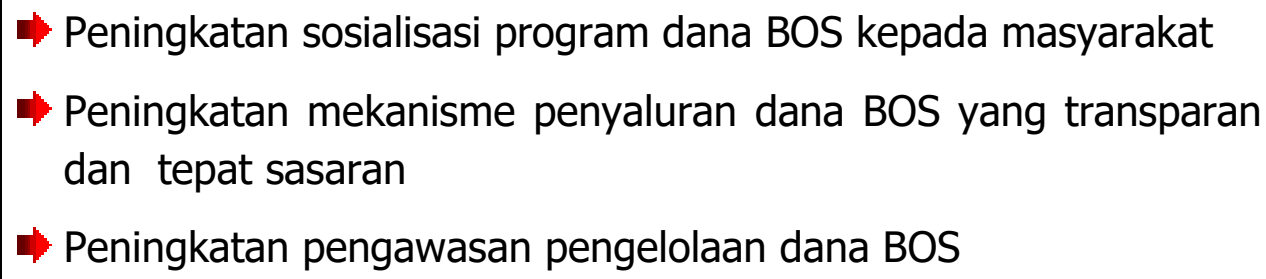 \\
\hline 7 & $\begin{array}{l}\text { Peningkatan } \\
\text { efektifitas } \\
\text { Program Kejar } \\
\text { Paket A,B,C }\end{array}$ & $\begin{array}{l}\text { Peningkatan } \text { profesionalisme } \\
\text { manajemen PKBM dan } \\
\text { peningkatan peranserta } \\
\text { masyarakat, organisasi dan } \\
\text { kelembagaan sosial dalam } \\
\text { pengembangan program Kejar } \\
\text { Paket } A, B \text {,dan C }\end{array}$ & $\begin{array}{l}\text { - Sosialisasi Kejar Paket kepada masyarakat dan stake holders, } \\
\text { khususnya kepada anak putus sekolah dan orang tua } \\
\text { क Peran serta Pesantren Salafiyah yang tidak menyelenggarakan } \\
\text { pendidikan formal untuk penyelenggaraan program Kejar Paket } \\
\text { untuk santrinya } \\
\text { Kampanye kepada anak dan remaja (usia } 7 \text { s.d. } 24 \text { tahun) yang } \\
\text { putus sekolah/tidak menamatkan sekolah hingga lulus SLTA } \\
\text { untuk mengikuti Kejar Paket A } \\
\Rightarrow \text { Pelatihan manajemen pengelolaan bagi PKBM-PKBM yang ada. } \\
\Rightarrow \text { Memberikan kemudahan dan menghilangkan pembiayaan } \\
\text { pengurusan ijazah penyetaraan }\end{array}$ \\
\hline 8 & $\begin{array}{l}\text { Peningkatan } \\
\text { efektifitas } \\
\text { Program } \\
\text { Indonesia Pintar } \\
\text { (PIP) }\end{array}$ & $\begin{array}{l}\text { Peningkatan } \quad \text { peranserta } \\
\text { sekolah, } \\
\text { pendidikan } \\
\text { (pesantren, lembagaan } \\
\text { PKBM, yayasan dan lainnya } \\
\text { serta masyarakat umumnya } \\
\text { dalam pelaksanaan program }\end{array}$ & $\begin{array}{l}\text { Sosialisasi program secara intensif dan merata tentang program } \\
\text { dan cara pelaksanaanya kepada masyarakat } \\
\text { Meningkatkan kemitraan PIP dengan sekolah, pesantren, } \\
\text { lembaga kursus, PKBM, yayasan dan lainnya dalam seleksi dan } \\
\text { pemantauan pelaksanaan PIP }\end{array}$ \\
\hline 9 & Memperbanyak & Mendorong dan memberikan & perguruan-perguruan tinggi \\
\hline
\end{tabular}

8|Fakultas Keguruan dan IImu Pendidikan Univ. MH Thamrin 


\begin{tabular}{|c|c|c|}
\hline $\begin{array}{l}\text { perguruan tinggi } \\
\text { di Kabupaten } \\
\text { Tangerang }\end{array}$ & $\begin{array}{l}\text { kemudahan kepada } \text { dunia } \\
\text { usaha, organisasi guru, ormas } \\
\text { pendidikan seperti } \\
\text { NU,Muhamadiayah, M. Anwar } \\
\text { dan lainnya untuk mendirikan } \\
\text { Pequruan Tingqi di Tangeranq }\end{array}$ & $\begin{array}{l}\text { sekolah umum } \\
\Rightarrow \text { Pendirian peguruan-perguruan tinggi agama bagi lulusan } \\
\text { sekolah agama } \\
\text { Memfasilitasi Perizinan pendirian perguruan tinggi di Kabupaten } \\
\text { Tangerang }\end{array}$ \\
\hline
\end{tabular}




\section{Kesimpulan Dan Rekomendasi}

Berdasarkan hasil penelitian, rendahnya indeks pendidikan di Kabupaten tidak terlepas dari beberapa faktor diantaranya: masih banyaknya anak putus sekolah; masih kurangnya kesadaran sebagian orang tua dan masyarakat terhadap pendidikan anaknya; belum meratanya sarana, fasilitas dan tenaga pendidikan dalam pendidikan dasar dan menengah; kesenjangan pendidikan antara perkotaan dan di wilayah pelosok desa; belum efektifnya pelaksanaan program wajar 9 tahun dan program lainnya seperti program penyetaraan paket A, B dan C, program Indonesia Pintar (PIP), program dana BOS dan lainnya; belum maksimalnya pengembangan partisipasi masyarakat dan kelembagaan/organisasi masyarakat dalam peningkatan penyelenggaraan pendidikan, dan faktor lainnya.

Indeks Pendidikan di Kabupaten Tangerang memiliki potensi untuk meningkat secara signifikan. Untuk itu, perlu program akselerasi peningkatan indeks pendidikan dengan berpijak pada upaya pengembangan semaksimal mungkin kekuatan dan potensi pendidikan yang dimiliki oleh wilayah dan masyarakat Kabupaten Tangerang diantaranya: anggaran belanja sektor pendidikan yang besar; keberadaan lembaga pendidikan dasar dan menengah yang cukup banyak; potensi banyaknya kelembagaan masyarakat, yayasan, PKBM, lembaga kursus, serta potensi lainnya untuk peningkatan pendidikan di Kabupaten Tangerang.

Mengacu pada hasil analisis data pada penelitian Indek Pendidikan di Kabupaten Tangerang, maka direkomendasikan :

1) Untuk Pemerintah Daerah Kabupaten Tangerang direkomendasikan untuk melaksanakan program akselerasi peningkatan indeks pendidikan diantaranya : Pencegahan dan penanggulangan anak putus sekolah, peningkatan kelulusan pendidikan anak minimal SMA/MA; peningkatan pemerataan pendidikan antara kota dan pedesaan; peningkatan mutu pendidikan dasar dan menengah; penyetaraan mutu pendidikan swasta dengan sekolah negeri; peningkatan efektifitas pengelolaan dana BOS, Kejar Paket, Program Indonesia Pintar (PIP); memperbanyak perguruan tinggi di Kabupaten Tangerang; serta peningkatan peran serta masyarakat, kelembagaan/organisasi masyarakat, pondok pesantren dan simpul-simpul komunitas lainnya di Kabupaten Tangerang dalam pendidikan.

2) Untuk masyarakat, kelembagaan/organisasi masyarakat, lembaga dan yayasan pendidikan, pondok pesantren dan kelompok masyarakat yang terdpat di Kabupaten Tangerang direkomendasikan untuk beperan serta dalam penyelenggaraan pendidikan; mensosialisasikan dan beperan serta dalam program-program wajar, kejar paket, PIP dan lainnya sesuai aturan dan kapasitasnya; meningkatkan kesadarandan motivasi kepada masyarakat tentang pentingnya pendidikan.

3) Untuk Pemerintah Daerah Provinsi Banten, Kementerian Pendidikan dan Kebudayaan, Kementerian Agama dan intansi tekait lainnya untuk dapat mendukung program akselerasi peningkatan indeks pendidikan di Kabupaten Tangerang dengan melakukan penyelarasan program-programnya sesuai dengan kebutuhan dan program yang dicanangkan oleh Pemda Kabupaten Tangerang.

\section{Referensi}


Buku profile kab. Tangerang tahun 2017

Simanjuntak, Payaman. J. 2008. Pengantar Ekonomi Sumber Daya Manusia. Lembaga

Penelitian FE UI. Jakarta. Hal.25

Maulana, R. \& Bowo, P. A. (2013). Pengaruh Pertumbuhan Ekonomi, Pendidikan dan

Teknologi terhadap IPM Provinsi di Indonesia 2007-2011. Journal of Economics and Policy.

$6(2), 163-169$.

UNDP, Human Development Report, 2008

Charisma Kuriata Ginting S, dkk (2008) melakukan penelitian yang berjudul "Pembangunan Manusia di Indonesia dan Faktor-Faktor Yang Mempengaruhinya, Economics Development Analysis Journal. Vol 1 November 2012

Astri Winarti, Analisis Pengaruh Pengeluaran Pemerintah Bidang Pendidikan, Kemiskinan, dan PDB terhadap Indeks Pembangunan Manusia di Indonesia Periode 1992-2012. Skripsi;

Repasitory Perpustakaan Universitas Diponegoro

UNDP. 1995. "Human Development Report” United Nations Development Programme. New York UNDP. 1996. "Human Development Report" United Nations Development Programme. New York UNDP. 1997. "Human Development Report" United Nations Development Programme. New York 